\title{
TERRITORIAL DISTRIBUTION OF PROJECTS CONTRACTED AT THE LEVEL OF COHESION POLICY 2014 - 2020
}

\author{
Florian Marin ${ }^{1}$ \\ *Corresponding author E-mail: marinflorian_21@yahoo.com
}

\begin{abstract}
A R T I C LE IN F O
A B S T R A C T

Original Article

Received: 08 January 2020

Accepted: 07 February 2020

doi:10.5937/ekoPolj2001107M

UDC 342.15:339.9"2014-2020"

Keywords:

Cohesion Policy, operational programs, European funds, absorption, territoriality.

JEL: M20, M48, M49

The article aims to identify the territorial distribution of the projects contracted within the operational programs that form an integral part of the Cohesion Policy 2014 2020. The analysis is performed in the context in which the territoriality of the investments financed by the Cohesion Policy represents an important variable for ensuring its success. In this article, we proceeded to identify the investment profile used by each county, profile exposed based on a methodology of calculation based on the themes financed by each operational program respectively of the projects contracted at the level of each operational program. Two variables were used in the analysis, namely the number and value of the projects contracted until 30.09.2019. The article highlights the existence of a significant territorial concentration of the projects contracted at the level of a small number of counties. Also, the infrastructure and regional development are the needs considered to be the most present at the level of the projects contracted at the level of Cohesion Policy.
\end{abstract}

(C) 2020 EA. All rights reserved.

\section{Introduction}

Cohesion policy is one of the most important policies of the European Union, it integrates one of the fundamental values of the European Union, namely cohesion. Eliminating development differences but also an unequal distribution of added value achieved at European level are the main motivations that justified the existence of Cohesion Policy. Although the need for such a policy is more than clear and necessary, this situation is mainly due to the extension of the European Union to Eastern Europe. The perception regarding the Cohesion Policy is different from one Member State to another or from one stakeholder to another. While some entities and Member States consider that Cohesion Policy aims at convergence, others consider that it aims at competitiveness, thus having significant perception difficulties regarding Cohesion Policy. However,

1 Florian MARIN, PhD Student, Academy of Economic Studies, Piața Romană 6, București 010374, Bucharest, Romania, marinflorian_21@yahoo.com, ORCID ID (https://orcid. org/0000-0002-0602-5036)

http://ea.bg.ac.rs 
Cohesion Policy benefits from one of the largest budgets, which is distributed among the Member States based on economic and social indicators. The 2014-2020 programming period targets an EU allocation for Cohesion Policy for Romania of just over 36 billion euro. Cohesion policy has become one of the main investors in the regional development processes at the level of Romania, the investments being realized through several operational programs managed in partnership by the Member State and the European Commission. How the operational programs are realized, administered but also correlated with the real needs of development determines the success of the Cohesion Policy, this statement precisely concerns the controversies regarding the capacity of the Cohesion Policy to reduce the regional disparities. While some experts consider that Cohesion Policy provides a defining contribution to the harmonious development of European regions, other experts do not consider that it influences the development processes considering its impact to be insignificant.

Cohesion policy is implemented by several institutions, each with its role, which ultimately assumes the responsibility of converting financial resources into concrete investment projects. The financial capacity, the existence of clear access and administration rules, the synergy between the financed projects and the real needs of the economic and social environment are some of the elements that influence the implementation of the operational programs, implicitly the success of the Cohesion Policy. To all these, we add a defining element for the characteristics of the Cohesion Policy, namely the access to investments financed under this policy or the territorial distribution of absorption. Cohesion policy must, first and foremost, ensure that absorption is directed to those regions that have a low level of development, the investments made from European funds aimed at reducing the level of development. The territorial distribution of absorption represents a study variable addressed in this article and which offers an answer regarding the implementation of Cohesion Policy in Romania.

\section{Literature review}

Integration is seen as a process of reducing disparities between regions and this approach can be attributed to a specific European model of integration (Garrido et all, 2007). Cohesion policy was built as a policy whose main objective is to reduce development disparities between the poor and rich regions of Europe. Cohesion policy is considered to be the EU's main investment instrument for achieving the "Europe 2020" objectives, which include: job creation and growth, combating climate change and energy dependence, and reducing poverty and social exclusion (European Commission, 2014). In the programming period 2014 - 2020, the development differences between the center and the periphery are very pronounced, and the Cohesion Policy must integrate a series of solutions to the problems that derive from these development differences (Jovančević, 2012). While some studies support a clear connection between cohesion and convergence such that some authors do find evidence of a positive impact of structural funds on economic growth (eg, Dall'erba, 2005; Ramajo et al., 2008), others state a series of malfunctions regarding the European project and the policies that 
derive from it (Bostan et all, 2016). Numerous studies have shown that structural funds have a positive impact on economic growth (Mohl \& Hagen, 2010; Eggert et al., 2007; Bouvet, 2005; Cappelen et al., 2003). At the same time, other analyzes conducted on the impact of structural funds, part of EU policies, including Cohesion Policy, have revealed that structural funds are irrelevant to economic growth (Percoco, 2005; Bussoletti \& Esposti, 2004; Esposti \& Bussoletti, 2008) or that there is no connection between economic growth and structural funds (Dallerba \& Le Gallo, 2008; GarcýaMila \& McGuire, 2001). The European Commission itself considers that there is a level of inefficiency in terms of structural funds, which is linked to the allocation of resources on different operational programs, sacrificing practically a tangible impact (European Commission, 2010). The thematic concentration of resources on several European priorities, as configured by the Cohesion Policy in the 2014-2020 programming period, is considered a positive step but will not solve the whole set of dilemmas regarding the cohesion concept, especially as regards the cohesion concept the antagonism between regional equity and the competitiveness of the European economy (Begg, 2010). The lack of a unanimously accepted opinion in the specialized literature imposes an analysis that takes into account the particularities existing at the level of each Member State because the context, the development needs but also the level of involvement of the stakeholders are different from one Member State to another so that it is impossible to illustrate a valid general rule.

\section{Methodology}

The analysis of the territoriality of the absorption of the European funds was carried out by sorting the projects approved at the level of the operational programs that constitute an integral part of the Cohesion Policy to identify the projects that benefit from territorial applicability at the level of a county. The reference unit for the analysis process is the county. After the process of sorting the projects, they were distributed on operational programs and mathematical and statistical formulas were applied, taking into account the particularities of the operational program and the strategic and programmatic architecture related to the programming period 2014 -2020. The project sorting process was realized based on the implementation region respectively of the county declared in the projects submitted and approved until 30.09.2019. Programs included in the analyze are Operational Program for Large Infrastructure (OPLI), Regional Operational Program (ROP), Operational Program for Human Capital (OPHC), Operational Program for Competitiveness (OPC), Operational Program for Administrative Capacity (OPAC), Operational Program for Technical Assistance (OPTA).

Using the weight of the values of the projects contracted at the operational program level in conjunction with the theme and the needs financed by each operational program, the thematic influence at the level of each county was identified. Specifically, the needs were distributed to operational programs, following the provisions of the Partnership Agreement 2014 - 2020 and after that, the following formula was applied: 
Infrastructure and regional development $=$

$\frac{O P L I}{\text { Total value of the projects }} \%+\frac{\text { ROP }}{\text { Total value of the projects }} \%$

Human capital, education, poverty reduction $=\frac{O P H C}{\text { Total value of the projects }} \%$

Innovation, research and development $=\frac{O P C}{\text { Total value of the projects }} \%$

Public administration and technical assistance = $\frac{\text { OPAC }}{\text { Total value of the projects }} \%+\frac{\text { OPTA }}{\text { Total value of the projects }} \%$

\section{Contracting under the Cohesion Policy 2014 - 2020 - 30.09.2019}

Contracting is a variable that provides an image of the level of absorption within an operational program or policy. Contracting is the first stage of the absorption process, which is extremely important because it integrates all the rules and responsibilities that a beneficiary of a project funded from European funds must fulfil. Contracting must be differentiated from absorption because it does not represent effective absorption but the level of contracting provides a predictable image regarding the level of absorption. The graph below illustrates the situation of Cohesion Policy contracting, on 30.09.2020.

Figure 1. The situation of the projects delimited territorially at county level - number of projects, 30.09 .2020

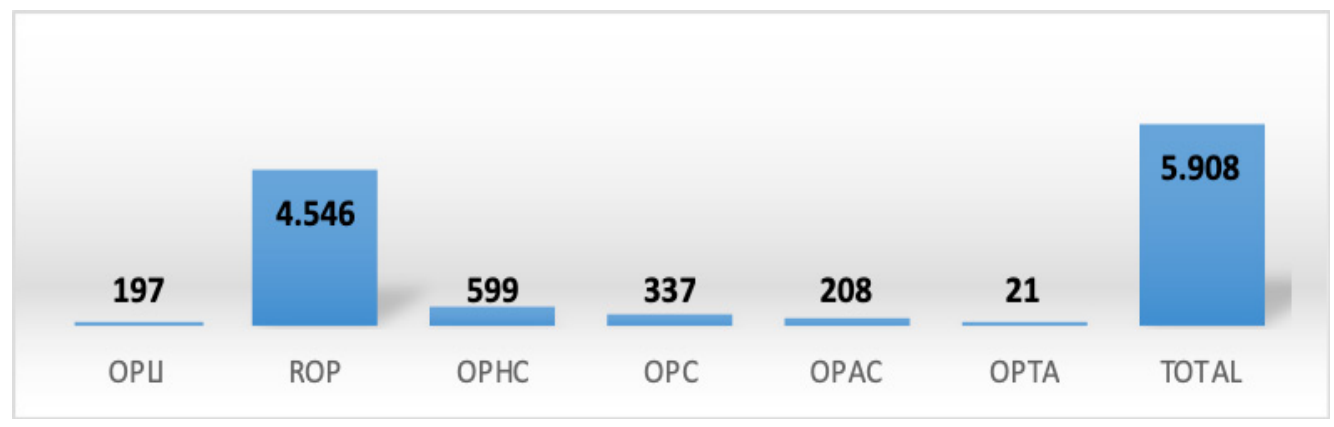

Source: Ministry of European Funds, 2019

Projects with a delimited territorial variable, more precisely those projects that are implemented at the level of a single county, total 5.908 projects. This number concerns the programs related to the Cohesion Policy 2014 - 2020, respectively the programming period 2014 - 2020. The analysis of the number of projects at the level of each program is an important variable for the characterization of the territoriality because it provides 
an image regarding the territoriality at the operational program level but also the centralization of the administration process used by the managing authority. OPLI is a program that assumes high values at the project level by financing large infrastructure so that projects financed by OPLI usually target several counties. 197 such projects explicitly target a certain county of Romania. OPHC integrates 599 projects that are territorially clear and related to one or more counties, OPC 337 of such projects, OPTA of 21 such projects. ROP is the program with the most projects with a clearly defined territorial variable, more precisely 4.546 such projects, about $76 \%$ of the projects related to the Cohesion Policy 2014 - 2020. It can be appreciated the existence of a more decentralized approach in the case ROP than for other operational programs, such as OPTA, for example.

Figure 2. The value of the projects delimited territorially at county level - lei, 30.09.2019

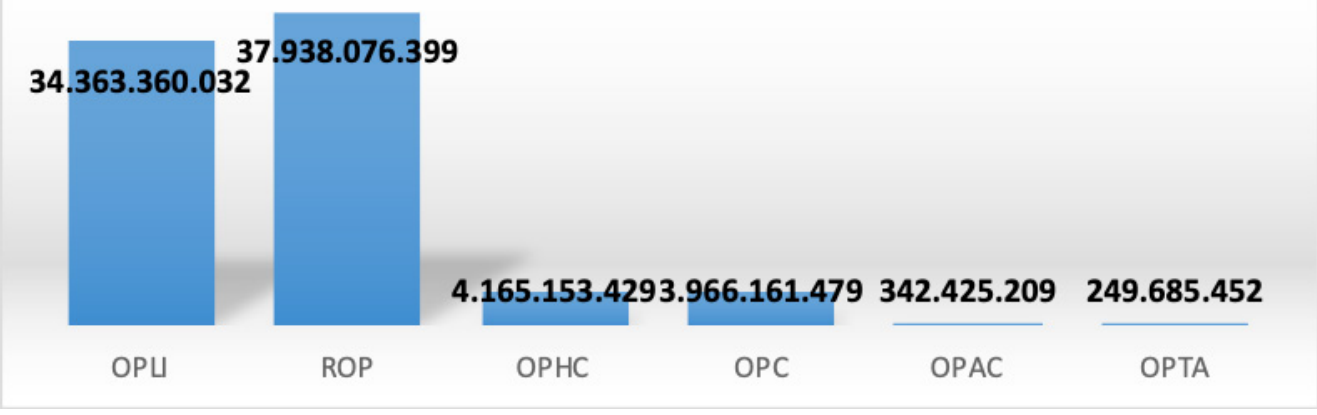

Source: Ministry of European Funds, 2019

Analyzing the situation of the projects delimited territorially at the county level we can observe that OPLI has delivered consistent value to these types of projects, namely 34.363.360.032 lei. At the same time, the ROP financed projects with a territorial value of 37.938.076.399 lei. Both programs mentioned above concerned contracted values by $82,84 \%$ of the EU allocation for OPLI and $122,9 \%$ of the EU allocation for ROP. At the same time, OPHC, a program with a rather well-defined territorial applicability, financed projects with a territorial value of 4.165.153.429 lei, representing only $21,17 \%$ of the EU allocation for the programming period 2014 - 2020. A slightly higher value for these types of projects, value established based on signed contracts, we can find it at the OPC this being of 3.966.161.479 lei representing 66,28\% of the EU allocation. OPAC targeted territorially delimited projects worth 342.425.209 lei and OPTA of 249.685.452 lei.

\section{Operational Program for Large Infrastructure (OPLI)}

OPLI aims to finance large infrastructure projects, benefiting from one of the largest allocations from the level of Cohesion Policy, in Romania. The EU allocation for OPLI is 9.218.524.484 euro, which is structured in 8 priority axes. The concrete topics addressed at the program level are transport, environment and climate change or energy 
and energy efficiency. The effective absorption at 01.11 .2019 at the program level was 19,31\%, which includes projects from 2007 - 2013, respectively phased projects.

Figure 3. The situation of the territorially delimited projects financed from OPLI - number of projects, 30.09.2020

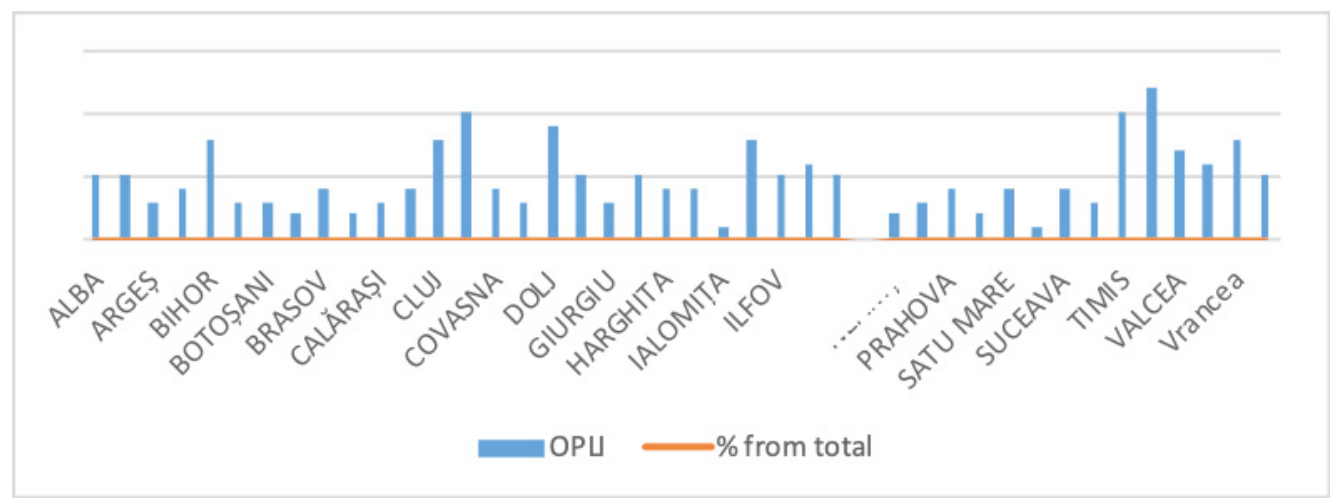

Source: Ministry of European Funds, 2019

The graph above illustrates the territorial distribution of the projects financed by OPLI. The graph shows that 7 counties cover $32,99 \%$ of the total number of projects financed from OPLI, each county having at least 8 projects contracted. At the same time, some counties have not contracted any project within this program, referring here to Mures. The Ialomita benefited from a single project and the counties of Braila, Buzau, Neamt or Salaj each benefited from 2 projects funded within the OPLI. The concern of the counties for the large infrastructure is present in most of the counties in Romania, this being considered one of the most important problems at the country level. The number of projects varies from county to county but except for one, all counties have benefited from at least one project funded by OPLI.

Figure 4. The situation of the territorially delimited projects financed from OPLI - lei, 30.09.2019

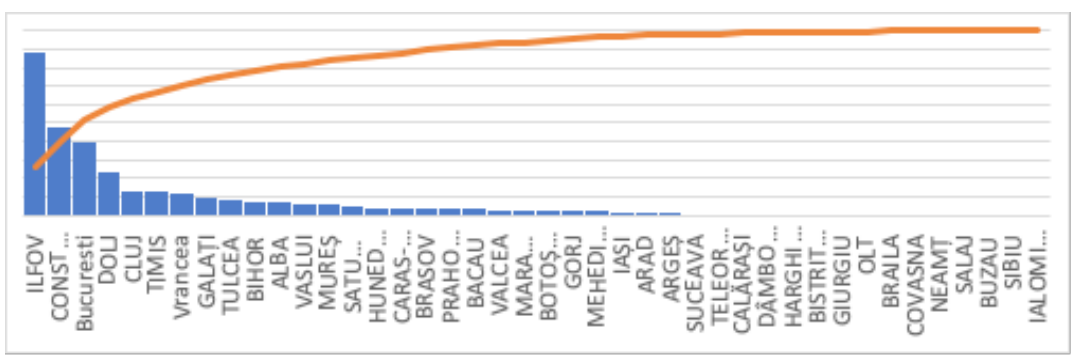

Source: Ministry of European Funds, 2019

Analyzing the distribution of the value of the projects financed from OPLI we can observe a significant difference from the situation of the distribution of the number of projects. 4 counties weight $58,66 \%$ of the total value of the territorially delimited 
projects contracted from OPLI. The Bucharest Ilfov region has realized projects that cover $37,6 \%$ of the value of the projects contracted and financed within the OPLI. An atypical example is the Tulcea county, which although it has a dedicated allocation and special selection procedures because it is under the Integral Territorial Investments instrument, it has realized projects worth only 865.893.101 lei, a value much lower than in counties such as Constanta. The value of the contracted projects is concentrated in a small number of counties, so that the projections regarding the absorption of the funds aimed at this program neglecting the development needs of the relatively poorer counties, such as Covasna or Dambovita.

\section{Regional Operational Program (ROP)}

ROP has an allocation of 6.860.000.000 euro in 2014-2020, representing the amount with which the EU contributes to the implementation of the program. On 01.11.2019 the payments to beneficiaries made under the program were 1.322.792.772 euro and the current absorption was 981.268.227 euro, representing 14,3\%. The absorption at 5 years from the start of the implementation period is considered to be small. ROP is an extremely important program for the mix of economic and social development provided for in the Partnership Agreement 2014 - 2020, which aims at needs such as technology transfer, SME competitiveness, urban development, social and educational infrastructure, tourism development or urban regeneration. These needs are structured based on 15 priority axes, 3 of them taking over a series of investment needs and objectives during the 2007-2013 programming period

Figure 5. Situation of the territorially delimited projects financed from OPLI - number of projects, 30.09.2020

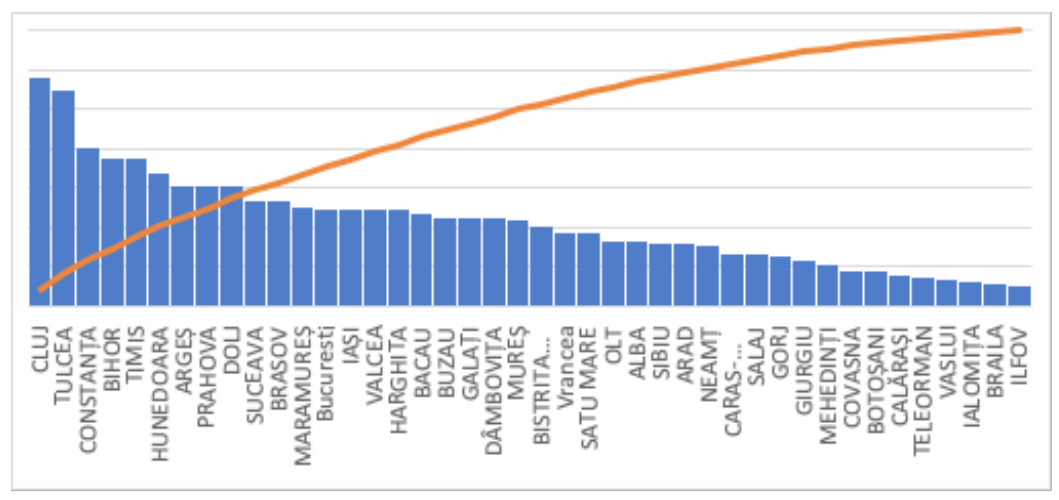

Source: Ministry of European Funds, 2019

Analyzing the situation of the territorially delimited projects contracted within the ROP we can observe a much more uniform distribution than in the case of OPLI. By 30.09.2019 ROP, 4.546 projects were contracted and financed by ROP, this being a large one. All the counties in Romania have benefited from projects funded within the ROP, this being one specific to this operational program. Their number differs from 
one county to another. Three counties benefit from more than 200 contracted projects, these being Cluj (292 projects), Constanta (202 projects) and Tulcea (276 projects). On the other side, we can see counties with a much smaller number of projects contracted within the ROP, exemplifying here Ilfov (28 projects), Braila (29 projects), Ialomita (32 projects), Vaslui (36 projects). Two particular examples should be mentioned, namely Tulcea County and Bucharest Ilfov region. Tulcea County benefits from 276 projects representing $6,07 \%$ of the projects contracted within the ROP, this being allowed by the particularities aimed at the evaluation and selection of projects within the Integrated Territorial Investments instrument. Another example is the Bucharest Ilfov region, which benefits from only 153 projects, the number is modest considering the characteristics of this region. The justification for such a small number derives from the fact that the Bucharest Ilfov region has restricted access to the opportunities offered by the ROP, with a small number of priority axes in which this region is eligible.

Figure 6. The value of the territorially delimited projects financed from the ROP - lei, 30.09.2019

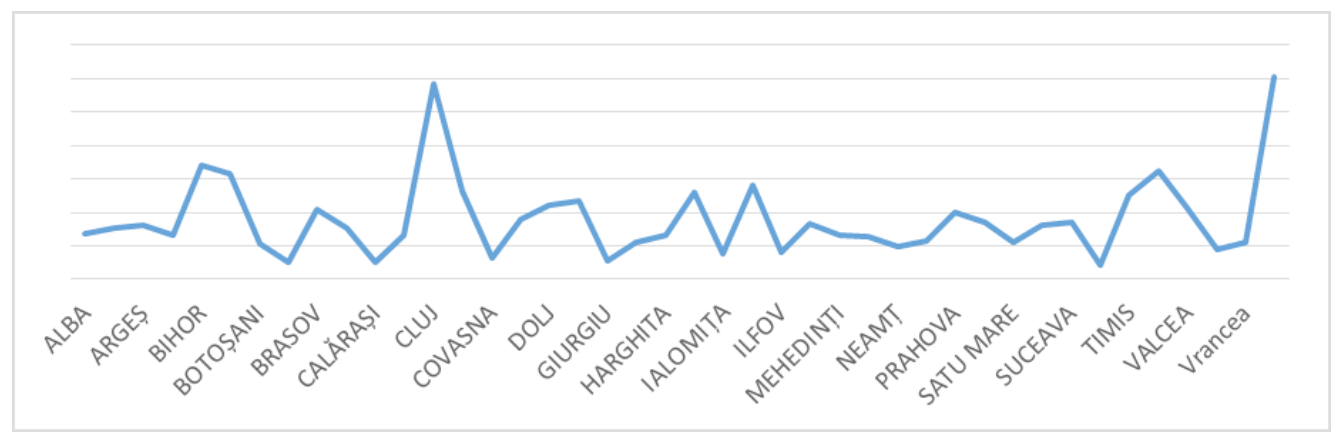

Source: Ministry of European Funds, 2019

The value situation of the projects financed from the ROP is different from that of the number of projects contracted. 3 counties benefit from 19,94\% of the total value of the projects contracted within the ROP (Cluj - 2.912.718.734 lei, Bucharest 3.031.937.557 lei, Tulcea - 1.619.478.733 lei). On the other side, we can identify a relatively large number of counties that do not exceed the weight of $1 \%$ of the total value of the projects contracted within the ROP, mentioning here the following counties: Braila (248.365.164 lei), Calarasi (258.738.697 lei), Covasna (329.218.623 lei), Giurgiu (282.630.033 lei) or Teleorman (218.654.838 lei). Notable performances can be seen in the case of the counties of Bihor (1.700.313.457 lei) and Bistrita Nasaud (1.582.581.477 lei). ROP is a program that benefits from different administration rules, which is implemented in a public-private way, more precisely through regional development agencies. The managerial flexibility but also the specific theme of this program allowed a much greater decentralization and a much more efficient adaptation to the regional and county particularities. 


\section{Operational Program for Human Capital (OPHC)}

The OPHC is an extremely important program for the Europe 2020 Strategy because it targets mainly social issues. More specifically, the topics covered by this program are the labour market, the correlation of the demand with the supply on the labour market, the efficiency of the educational system but also the reduction of poverty. The topics are structured based on 7 priority axes, 6 of them having immediate thematic applicability and one is dedicated to technical assistance. OPHC is an extremely complex program, the assertion being based on the extremely large number of beneficiaries with which the program interacts. The EU allocation for this program is 4.371.963.027 euro, which is considered a big one. The current absorption at 01.11.2019 was 927.748.759 euro $(21,22 \%)$ and the actual absorption was 776.875 .827 euro $(17,77 \%)$. One particular feature of this program is that the number of territorial projects does not exceed $50 \%$ of the total number of projects financed at the national level so that the level of centralization used by the managing authority is high.

Figure 7 . Situation of the territorially delimited projects financed from OPHC - number of projects, 30.09 .2020

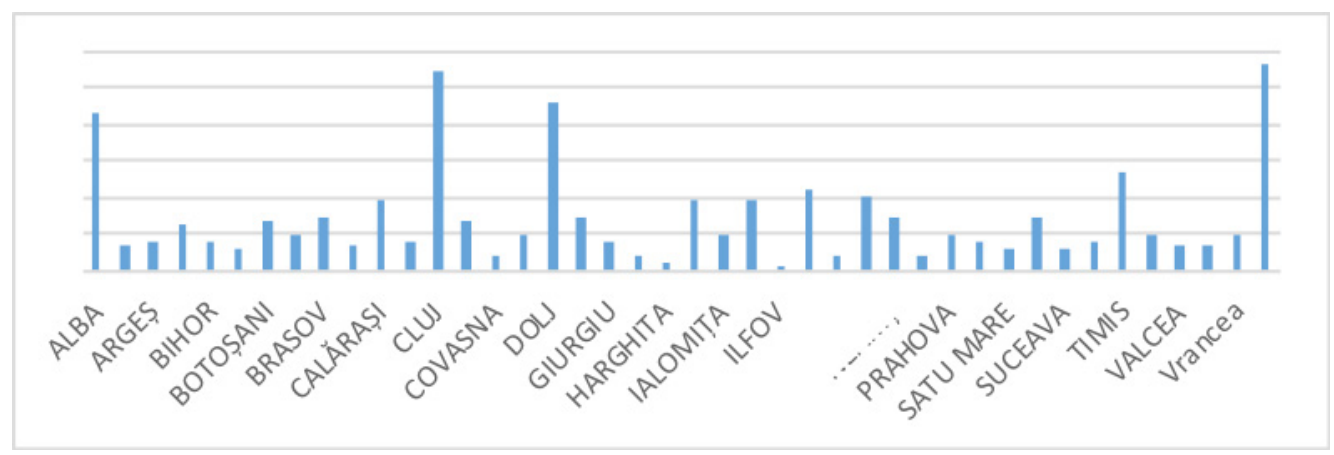

Source: Ministry of European Funds, 2019

All the counties in Romania have benefited from at least one contract with a delimited territorial characteristic, a project financed within the OPHC. The graph above shows a concentration of the contracted projects in a small number of counties, referring here to Alba (43 contracts), Dolj (46 contracts), Cluj (54 contracts) or Bucharest (56 contracts). As with other operational programs, we can observe a concentration of absorption in a limited number of counties, so that $25,54 \%$ of the absorption is concentrated in 4 counties. At the same time, Ilfov County benefited from a single project with the territorial delimitation financed by OPHC, being the only county in such a situation. At the same time, Harghita contracted 2 projects from OPHC, Mehedinti, Gorj and Olt with 4 projects each, these being the counties with the least number of projects contracted within the OPHC. 
Figure 8 . The value of the territorially delimited projects financed from OPHC - lei, 30.09.2019

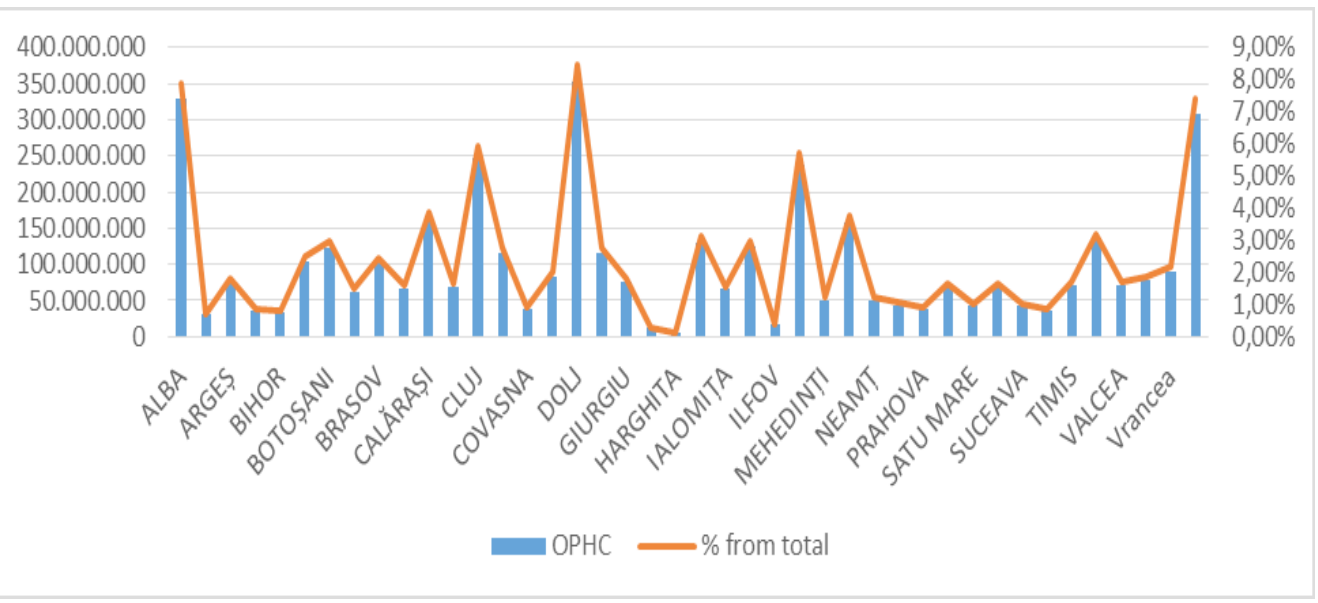

Source: Ministry of European Funds, 2019

Analyzing the distribution of the amounts contracted within the OPHC we can observe more efficient counties in attracting the amounts that come from the OPHC, these are Alba (329.528.042 lei), Dolj (352.654.917 lei), Maramures (237.805.154 lei) or Bucharest (308.957.552 1ei). A particular example is Tulcea County, which benefits from contracts amounting to 133.703.101 lei. At the same time, the counties that have benefited from the smallest amounts contracted based on the projects financed from OPHC are the following: Arad (30.152.926 lei), Gorj (12.002.450 lei), Harghita (4.403.655 lei), Ilfov (16.553.115 lei), Prahova (38.145.266 lei) or Teleorman (36.014.030 lei). The graph above shows an unequal distribution of the contracted values based on the projects financed from OPHC.

\section{Operational Program for Competitiveness (OPC)}

The OPC, unlike other operational programs, is much more flexible, benefiting from only two priority axes, its needs being research, technological development and innovation in support of economic competitiveness and business development as well as e-governance or facilitating high-speed Internet access. The OPC benefits from an allocation from the EU of 1.329.787.234 euro, the current absorption at 01.11.2019 being $21,98 \%$ and the effective one $18,8 \%$. The program is narrow, including thematically so that its implementation is much easier than in the case of other operational programs. The territorial distribution of absorption is shown in the graphs below: 
Figure 9. The situation of the territorially delimited projects financed from the OPC - number of projects, 30.09.2020

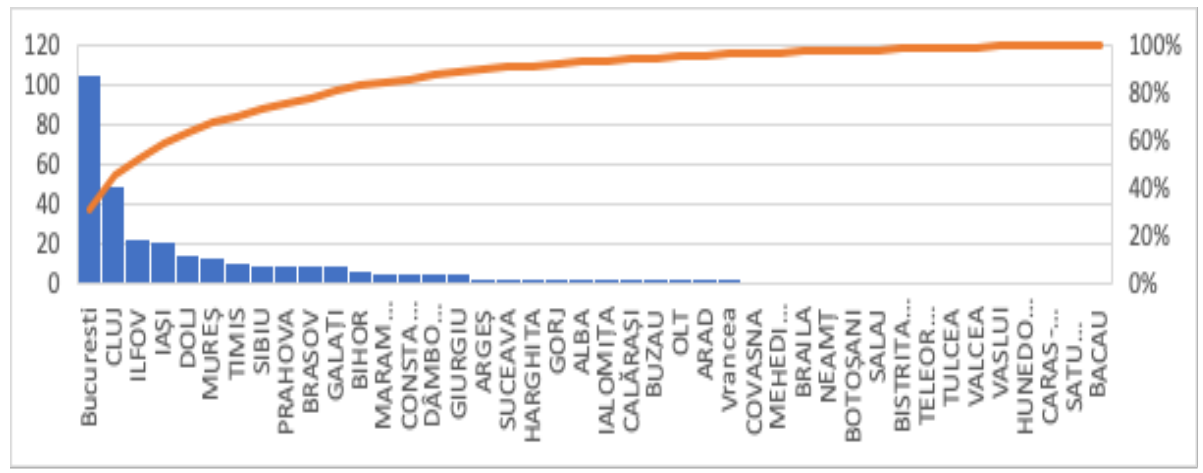

Source: Ministry of European Funds, 2019

The territorial distribution of the projects financed within the OPC is deeply concentrated in a small number of counties, this is clearly illustrated by the graph above. Bucharest has the largest number of projects contracted at the national level, twice as many projects as Cluj County, for example. Specifically, the number of projects delimited territorially, projects that were contracted within the OPC by the Municipality of Bucharest was 106 projects while in Cluj county 49 projects were contracted. 5 counties benefited from $63,5 \%$ of the projects contracted within the OPC, these being as illustrated in the graph above Bucharest, Cluj, Ilfov, Iasi and Dolj. At the same time, about half of the counties of the country either did not benefit from any project or have at most 2 projects contracted within the UCI. OPC is the program that delivers one of the largest territorial concentrations in terms of territorial distribution of projects contracted within the OPC.

Figure 10. The value of the territorially delimited projects financed from the OPC - lei, 30.09.2019

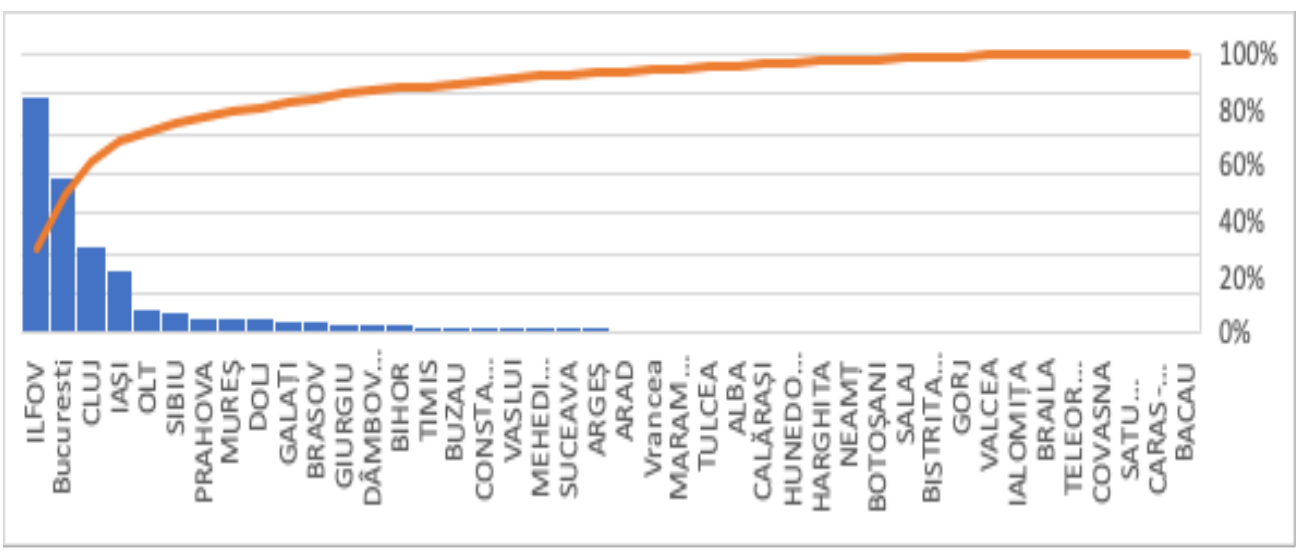

Source: Ministry of European Funds, 2019

http://ea.bg.ac.rs 
Analyzing the value territorial distribution of the OPC we can find that the territorial concentration encountered at the level of the projects contracted within the OPC is maintained. A notable difference is Ilfov County, they benefit from a much smaller number of projects than Bucharest, but it has a contracted value of about $40 \%$ higher than Bucharest. This is due to the projects of major importance found at the program level, an example would be the laser from Magurele. The value distribution of the amounts contracted within the OPC ensures a significant concentration in 4 counties, totalling $68,96 \%$ of the absorption representing 2.734 .887 .656 lei. The territorial concentration of absorption is significant at the level of the OPC.

\section{Operational Program Administrative Capacity (OPAC)}

OPAC is an operational program that integrates 3 priority axes, these mainly targeting the public administration and the judicial system. The amount allocated to this operational program is 553.191.489 euro, the EU allocation. The current absorption at 01.11 .2019 is 96.612 .709 euro representing $17,46 \%$ of the total allocation and the actual absorption was 82.914 .613 euro representing $14,99 \%$ of the total allocation. OPAC is an operational program aimed mainly at public authorities, the procedural synergy between the beneficiaries and the managing authority being much greater than in the case of other operational program. Also, the extremely limited thematic area but also the strategic framework dedicated exclusively to public administration make this program extremely attractive for the Romanian public authorities. This is proved by the territorial distribution of the contracts related to the projects financed from OPAC but also by the specific value distribution, these being presented in the graphs below.

Figure 11. The situation of the territorially delimited projects financed from OPAC - number of projects, 30.09.2020

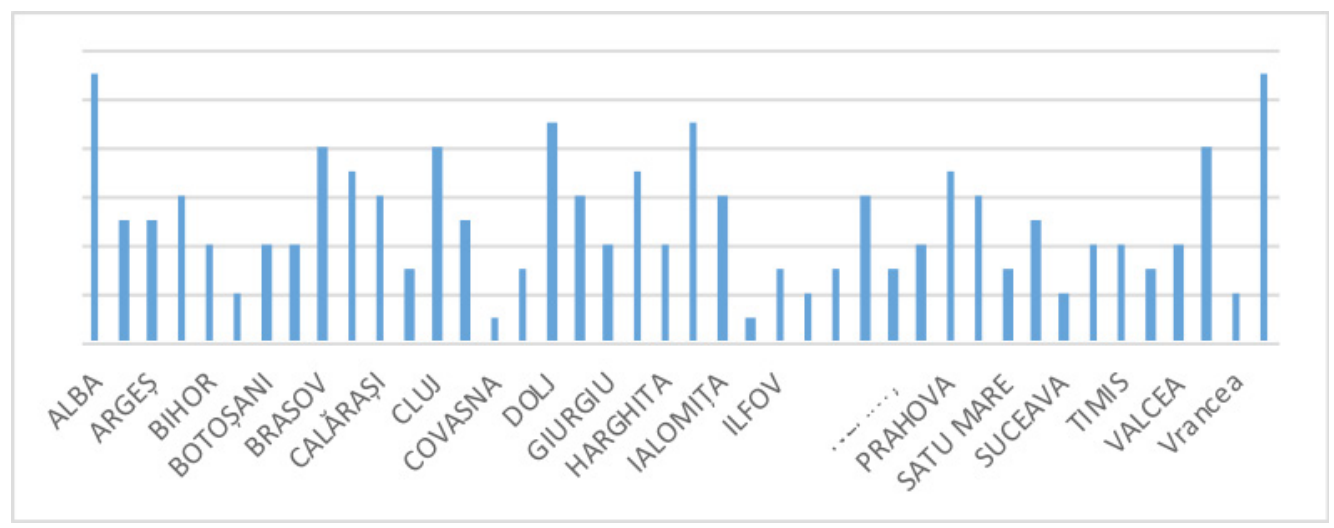

Source: Ministry of European Funds, 2019

The territorial distribution of projects with territorial applicability financed by OPAC is much more uniform compared to other operational programs. All the counties of the country have benefited from at least one project with the territorial delimitation financed 
from OPAC. The counties with the most projects are Alba (11 projects), Hunedoara (9 projects), Bucharest (11 projects). On the other hand, the counties that have benefited only from a project are Iași and Covasna, while Maramures, Bistrita Nasaud, Suceava and Vrancea have benefited from 2 projects with territorial delimitation financed by OPAC. Access to OPAC is considered easy because the level of expertise required for such a project is not a complex one but also within the reach of the beneficiaries, in this case, public authorities.

Figure 12. The value of the territorially delimited projects financed from OPAC - lei, 30.09.2019
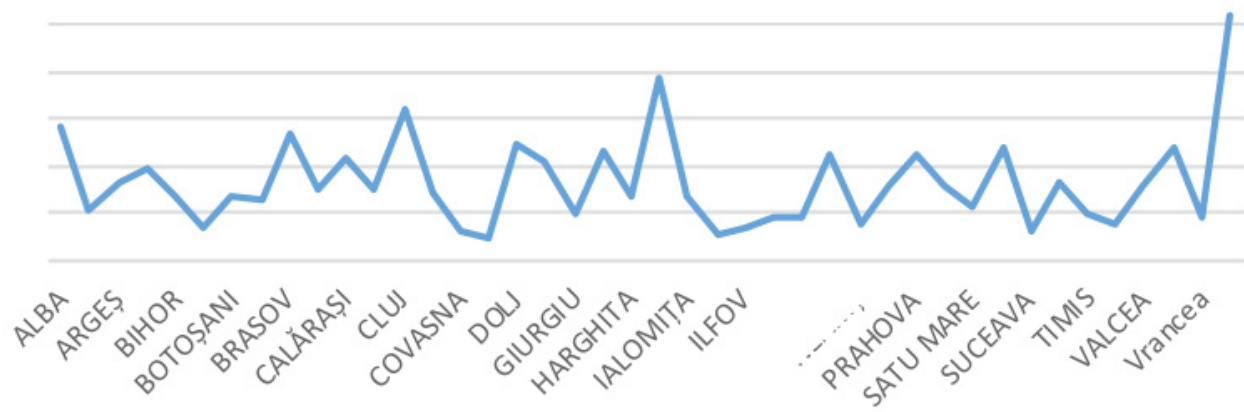

Source: Ministry of European Funds, 2019

In the case of the value distribution related to the projects with territorial delimitation contracted in the case of OPAC, we can observe differences from one county to another. Despite a much less territorial distribution of projects, in terms of value, we can see that 4 counties benefited by $21,44 \%$, the percentage is a significant one. The counties we refer to are Cluj, Dolj, Hunedoara and Bucharest. The counties that have registered modest performances in attracting the amounts related to OPAC by contracting the projects with the territorial delimitation are Covasna $(0,85 \%$ of the total value), Dambovita $(0,66 \%$ of the total value), Iasi $(0,77 \%$ of the total value) and Suceava $(0,91 \%$ of the total value $)$.

\section{Operational Program for Technical Assistance (OPTA)}

The EU allocation at the program level is 252.765.958 euro, this being the smallest allocation from the operational programs that can be found in the Cohesion Policy. The current absorption at 01.11.2019 was 128.071 .144 euro representing 50,67\% and the actual absorption was 109.206.327 euro representing 43,2\% of the total allocation. OPTA is the program that delivers the highest absorption on 01.11 .2019 , the program is structured based on two priority axes, the first aimed at the system of European structural and investment funds and the second aimed at promoting the structural instruments to increase the absorption rate. OPTA is a program different from the rest of the operational programs because the thematic area covered directly concerns the implementation of the structural instruments and the functioning of the management system. 
Figure 13. Situation of the territorially delimited projects financed from OPTA - number of projects, 30.09.2020

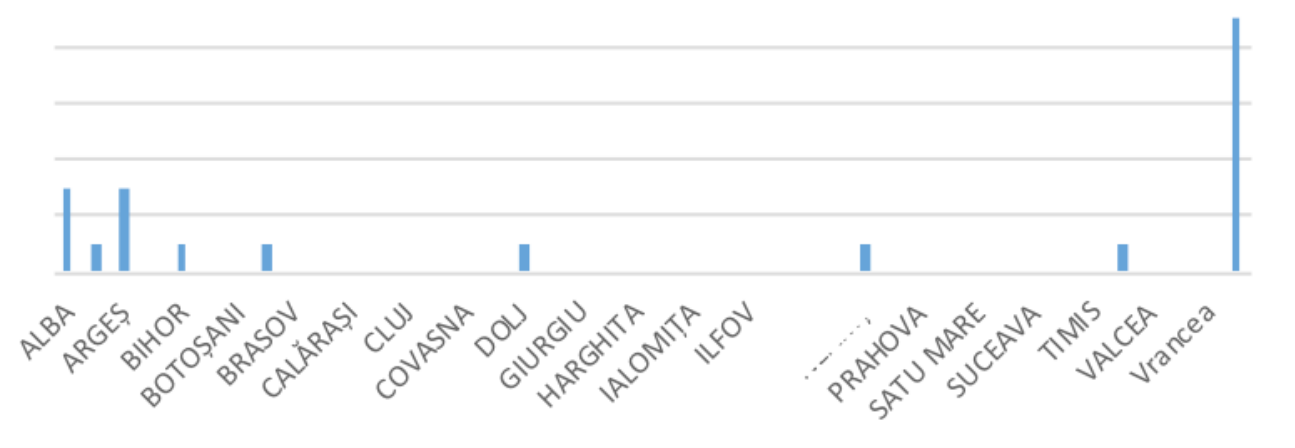

Source: Ministry of European Funds, 2019

The graph above illustrates that out of all the counties of Romania, only 9 have realized and contracted projects financed under OPTA. 9 of the 21 projects realized were realized in Bucharest and the only counties that have benefited from more than one OPTA funded project are Alba and Arges. The level of centralization that the program delivers is a significant one, as it has been observed the distribution of the contracted projects being an extremely territorial one. The situation of Bucharest derives from the fact that most of the central institutions are in Bucharest, this being the justification for a large number of territorially delimited projects found at the level of Bucharest.

Figure 14. Value of territorially delimited projects financed from OPTA - lei, 30.09.2019

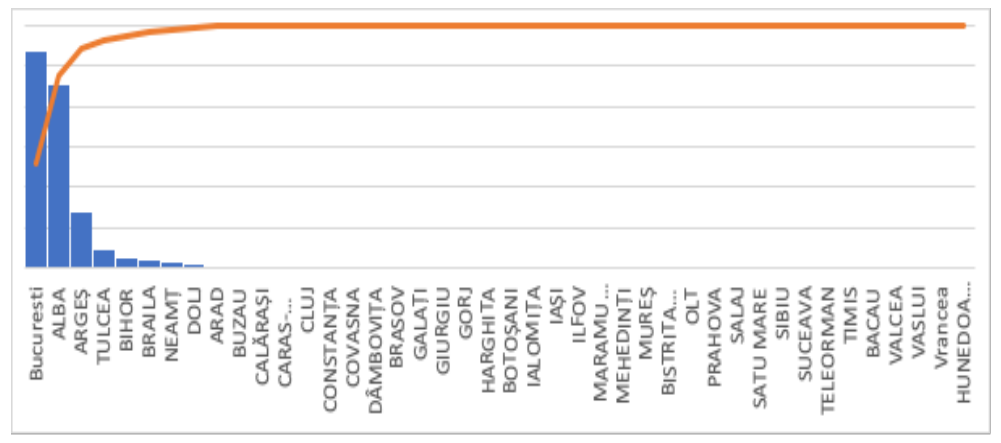

Source: Ministry of European Funds, 2019

The territorial distribution of the amounts proves a major concentration of the amounts contracted within the OPTA, more precisely we can find two counties that cover 79,74\% of the total of the contracted amounts. OPTA is the program with the highest thematic concentration in the Cohesion Policy. The two counties we refer to are Bucharest $(43,06 \%)$ and Alba (36,68\%). Also, Arges County benefited from a contracted value of 27.433.829 lei, representing $10,99 \%$ of the total value of the projects contracted under OPTA on 30.09.2019. 
Figure 15. Investment profile financed from European funds used at county level - \%

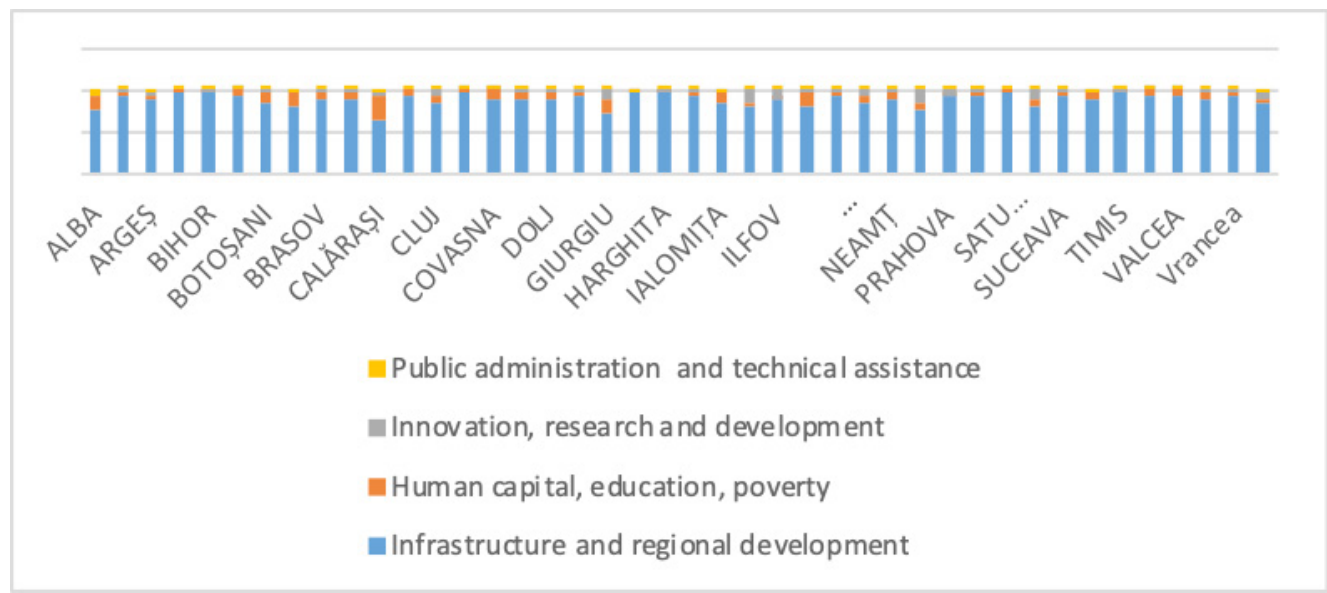

Source: Own processing

Based on the calculation formula set out in the methodology, we proceeded to identify the needs covered by projects with territorial delimitation contracted within the Cohesion Policy on 30.09.2019. The graph above illustrates the thematic mix used at the level of Cohesion Policies, it takes into account the territorially delimited projects, projects contracted until 30.09.2019. As can be seen, most of the counties in Romania have contracted projects that directly targeted the regional development and infrastructure, these needs are widely financed during the programming period 2014 2020. The integration of the theme related to regional development and infrastructure it is a consequence of the needs felt at the county level because those are the most prominent but also the most requested by the beneficiaries and stakeholders of the programming period 2014 - 2020. Addressing the investment theme at the county level is also a consequence of the modality in which was administered and implemented ROP. It delivered the largest number of projects with territorial delimitation, which is possible due to the thematic approach at the program level but also the structure of beneficiaries, these targeting the territories and needs delimited and applicable at the county level. ROP has delivered 4.546 projects with territorial delimitation. The need for infrastructure and regional development was integrated on average at the county level in the proportion of $88,19 \%$, a percentage calculated as the arithmetic average of all the percentages at the county level. Among the counties that have given the greatest interest to this topic, the interest manifested through the realized projects is Constanta (97,51\%), Bihor (96,53\%) or Bacau (95,77\%). Except for Calarasi County, all counties integrated the need for infrastructure and regional development in the projects contracted over $70 \%$, Calarasi county being the only one that addressed this need in a proportion of $63,86 \%$.

Regarding the need related to human capital, education and poverty we can observe a much higher concentration at the territorial level than in the previous case. The territorial 
concentration mainly concerns the counties of Alba (17,31\%), Calarasi (30,49\%), Giurgiu $(16,06 \%)$, Maramures (16,83\%) and Ialomita (13,92\%). The counties that have addressed the issues related to human capital, education and poverty in a small proportion are Ilfov $(0,16 \%)$, Harghita $(0,58 \%)$ or Bihor $(1,53 \%)$. Research development and innovation is a need that also delivers a significant level of territorial concentration so that the counties of Iasi $(15,12 \%)$, Giurgiu (10,2\%), Ilfov $(11,2 \%)$, Olt $(15,66 \%)$ and Sibiu $(11,25 \%)$ are the counties with the highest weight in terms of the previously mentioned topic. The situation is similar even in the case of public administration and technical assistance so that Alba County integrates this need in a proportion of $5,69 \%$, this being the county that has assigned the highest weight to this need.

\section{Conclusions}

The European funds have territorial applicability these generating effects at the level of a county respectively at the level of a region. The study of the mix of needs financed from the projects related to Cohesion Policy represents an endeavour to provide an image regarding the specific investment characteristics of a certain county, characteristics predefined by the beneficiaries from the respective county who have contracted projects financed from European funds. The managing authority but also other institutions that are an integral part of the system of European structural and investment funds can influence how the beneficiaries base their choices. Development needs are not the only elements that contribute to the substantiation of investment decisions at the level of a beneficiary, access to expertise or technical and operational capacity are also of utmost importance.

The analysis performed at the level of this article proves a different behaviour from one operational program to another regarding the territoriality of the funded projects. The most important operational program from this point of view is ROP, which has a thematic approach that best captures the development needs at the county level. It delivered 4.546 territorially delimited projects whose total value was 37.938.076.399 lei, EU allocation. OPLI is the program that has provided 197 territorially delimited projects whose EU allocation is 34.363.360.032 lei. We can see a significant difference between the two operational programs that finance the infrastructure. ROP targets small investments with county-level applicability, while OPLI is an investment-focused program targeting at least one or more counties or one or more regions. The differences regarding the number of projects are given including the fact that Romania is administered by counties while the funds are allocated and managed regionally. The complexity of an infrastructure project financed from OPLI is greater given a large number of institutions that intervene in the implementation and implementation of the respective project. From the number of projects, both OPLI and ROP are territorially dispersed so that most counties have benefited from at least one project funded from these programs. From the values of the contracted projects, we can observe a significant territorial concentration in the case of OPLI such that the Bucharest Ilfov region covered $37,6 \%$ of the total value of the projects contracted within the OPLI and 3 counties (Ilfov, Cluj, Constanta) and Bucharest Municipality. In the case of ROP, we can observe a less concentrated distribution such 
that the Municipality of Bucharest together with two counties covered 19,94\% of the total value of the contracted projects. A territorial concentration can be found even in the case of OPHC, this one concerning both the number of projects and the contracted values. More precisely 4 counties contracted $29,51 \%$ of the values contracted at the level of OPHC projects. The situation is similar in the case of OPTA, the territorial concentration being a much more pronounced one so that the Municipality of Bucharest together with Alba county contracted $79,74 \%$ of the total value of the contracted projects. OPAC is an operational program that has a lower territorial concentration than in the previous programs, its situation being approximately similar to that of the ROP. Specifically, 3 counties next to Bucharest Municipality concentrate $21,44 \%$ of the value of the contracted projects in the case of OPAC.

The implementation of the Cohesion Policy 2014 - 2020 is one that ensures a significant territorial concentration of absorption in a small number of counties. ROP and OPAC ensure a territorial concentration of about $20 \%$ in 3 or 4 counties while the rest of the programs deliver a concentration of at least $30 \%$, reaching up to $79,74 \%$ in the case of OPTA. Regarding the portfolio of projects at the county level, we can see that infrastructure and regional development are the most widespread needs financed. The counties that concentrate most of the absorption deliver a diverse investment portfolio. An example of a county that delivers a significant territorial concentration for most operational programs is Cluj. It contracted projects that targeted the infrastructure and regional development by $85,87 \%, 4,92 \%$ of the value of the contracted projects concerned the human capital, education and poverty reduction, $8,88 \%$ of the value of the contracted projects aimed at research and development and innovation also $0,32 \%$ of the value of the contracted projects concerning the public administration and the technical assistance. In general, the needs that have benefited from investments in most counties are related to infrastructure, education, human capital and education.

The orientation of the investments financed under the operational programs that make up the Cohesion Policy is rather oriented, both in value based on the contracted projects and in terms of the number of projects contracted, towards those counties with a higher level of development such as Cluj, Ilfov or the Municipality of Bucharest. During this time, counties such as Braila, Vaslui, Ialomita, Botosani registered modest performances in terms of contracting projects. There are significant differences from one county to another in terms of the portfolio of projects contracted until 30.09.2019 within the Cohesion Policy. The differences are justified by several elements that were not included in the analysis methodology, such as financial capacity, access to expertise, rules at the program level or the programmatic framework for the programming period 2014 -2020. For a justification of the causes which influence the territorial distribution of absorption, it is necessary to analyze at least the above-mentioned data.

\section{Conflict of interests}

The authors declare no conflict of interest. 


\section{References}

1. Garrido R., Mancha T., \& Cuadrado, J.R. (2007). Regional and cohesion policy in the European Union: twenty years of progress and a new future. Regional Investigations, 10, 239-266. [in Spanish: La política regional y de cohesión en la Unión Europea: veinte años de avance y un futuro nuevo. Investigaciones Regionales].

2. European Commission. (2014). General Union Environment Action Programme to 2020: Living Well, Within the Limits of Our Planet. Brussels: European Commission.

3. Jovančević R., Globan T., \& Recher V. (2015). Does the Cohesion Policy Decrease Economic Inequalities in the European Union?

4. Dallerba, S., \& Le Gallo, J. (2008). Regional convergence and the impact of European structural funds 1989-1999: A spatial econometric analysis. Papers in Regional Science, 82(2), 219-244.

5. Ramajo, J., Márquez, M., Hewings, G., \& Salinas, M. (2008). Spatial heterogeneity and interregional spillovers in the European Union: do cohesion policies encourage convergence across regions? European Economic Review, 52, 551-567.

6. Bostan, I., Popescu, C., Dascălu, E. D., \& Firtescu, B. N. (2016). The European Union Cohesion Policy and External Migration in Romania. Multistage Analysis. Revista de cercetare și intervenție socială, 54, 96-114.

7. Begg, I. (2010). Cohesion or Confusion: a policy searching for objectives. Journal of European Integration, 32(1), 77-96.

8. Mohl, P., \& Hagen, T. (2010). Do EU structural funds promote regional growth? New evidence from various panel data approaches. Regional Science and Urban Economics, 40(5), 353-365.

9. Bouvet, F. (2005). European Union regional policy: Allocation determinants and effects on regional economic growth. Department of Economics, University of California, Davis.

10. Cappelen, A., Castellacci, F., Fagerberg, J., \& Verspagen, B. (2003). The impact of EU regional support on growth and convergence in the European Union. Journal of Common Market Studies, 41, 621-644.

11. Percoco, M. (2005). The impact of structural funds on the Italian Mezzogiorno. 1994-1999, Region et Developpement, 21, 141-152.

12. Bussoletti, S., \& Esposti, R. (2004). Regional Convergence, Structural Funds and the Role of Agricolture in the EU. A Panel-Data Approach, (No. 220).

13. Esposti, R., \& Bussoletti, S. (2008). Impact of Objective 1 funds on regional growth convergence in the European Union: A panel-data approach, Regional Studies,42(2), 159-173.

14. Garcýa-Mila, T., \& McGuire, T. (2001). Do interregional transfers improve the economic performance of poor regions? The case of Spain, International Tax and Public Finance, 8, 281-295.

15. European Commission. (2010), Intereconomics, 136-170. Europa 2020: Competitivitate, cooperare și coeziune între toate regiunile, 2010, Panorama inforegio. 